\title{
Surgical Mortality in Infective Endocarditis: Is There a Gender Paradox?
}

\author{
Daniel Seabra ${ }^{10}$ and Cristina Gavina ${ }^{1,2,3}$ (D)

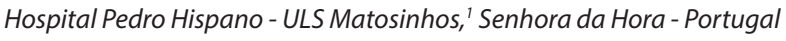 \\ Department of Medicine, Faculty of Medicine, Porto University, ${ }_{1}^{2}$ Porto - Portugal \\ Cardiovascular R\&D Unit (Un/C), Faculty of Medicine, Porto University, ${ }_{3}$ Porto - Portugal \\ Editorial referring to the article: Gender Based Analysis of a Population Series of Patients Hospitalized with Infective Endocarditis in \\ Portugal - How do Women and Men Compare?
}

Cardiovascular diseases (CVD) represent a global pandemic. Although mortality due to CVD has been decreasing with improvement in diagnosis and treatment, it remains the most frequent cause of death worldwide both in men and women. ${ }^{1}$

Gender impacts several key aspects in CVD, such as epidemiology, pathophysiology, clinical manifestations, disease progression, response to treatment and prognosis, in areas like coronary artery disease and heart failure. ${ }^{2}$ However, few studies analyzed the influence of gender in infectious endocarditis (IE) management and outcomes. ${ }^{3,4}$

IE is a relatively rare condition associated with dismal prognosis and an estimated mortality rate of $25 \% .{ }^{5}$ In recent years, there has been an epidemiological shift, affecting patients progressively older, with cardiac valvular prosthesis and devices, and in association with invasive procedures. Nevertheless, gender impact in IE is still at debate, with scarce information to elucidate its role in the disease. ${ }^{6}$

In the current issue of the International Journal of Cardiovascular Sciences, Catarina Sousa et al. ${ }^{7}$ reviewed the impact of gender on a Portuguese National Health System (NHS) cohort of hospitalized patients with IE, characterizing their clinical profile, therapeutic strategies, and outcomes. They collected discharge data on ICD-9 and ICD-10 codes for IE from the administrative NHS database between 2010-2018, and performed a comparative analysis based on gender for several variables of interest, including age,

\section{Keywords}

Endocarditis; Thoracic Surgery; post-operative mortality; Sex. cardiovascular history and comorbidities, infectious agents, IE complications, cardiac surgery in index hospitalization and post-operative and overall in-hospital death.

This nationwide cross-sectional study identified 7574 patients admitted for IE. There was a higher prevalence in men $(56.9 \%)$, who were younger and had a higher rate of comorbidities than women, except for arterial hypertension and atrial fibrillation. Notably, additional important differences were noted between women and men, especially concerning treatment strategies. Despite the lower prevalence of comorbidities and more frequent presentation with acute heart failure, women were less likely to undergo cardiac surgery during the incident hospitalization for IE and had a higher postoperative mortality rate, independent of other prognostic factors such as sepsis or acute renal failure. Even so, overall in-hospital mortality was comparable among men and women.

Although limited by the lack of important data as the frailty score, surgical risk scores, and time to surgery, this report provided additional information about an apparent paradox of higher surgical mortality in women, already described in other cardiac surgeries. ${ }^{8}$ In this cohort women were older, and these tend to be frailer than men. This is generally captured by

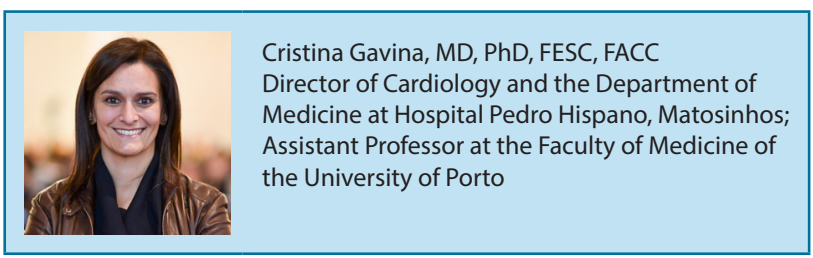

Mailing Address: Cristina Gavina

R. de Dr. Eduardo Torres, s/n. Postal Code: 4450-113, Sra. da Hora - Portugal

E-mail: cristina.gavina@gmail.com 
surgical risks scores, which weren't considered in the logistic regression analysis. An additional explanation for this intriguing question may be related to the fact that in this IE cohort males more frequently had more aggressive microbiological agents, with greater potential for severe valvular damage, favoring more frequent surgical strategy. Additionally, time to surgery can have impacted results once there are reports that early valve surgery is associated with

\section{References}

1. Mozaffarian D, Benjamin EJ, Go AS, Arnett DK, Blaha MJ, Cushman M, et al. Heart Disease and Stroke Statistics-2016 Update: A Report From the American Heart Association. Circulation. 2016;133(4):38-360. doi: 10.1161/CIR.0000000000000350.

2. Mauvais-Jarvis F, Merz NB, Barnes PJ, Brinton RD, Carrero JJ, DeMeo DL, et al. Sex and Gender: Modifiers of Health, Disease, and Medicine. Lancet. 2020;396(10250):565-82. doi: 10.1016/S0140-6736(20)31561-0.

3. Elamragy AA, Meshaal MS, El-Kholy AA, Rizk HH. Gender Differences in Clinical Features and Complications of Infective Endocarditis: 11-year Experience of a Single Institute in Egypt. Egypt Heart J. 2020;72(1):5. doi: 10.1186/s43044-020-0039-6.

4. Sevilla T, Revilla A, López J, Vilacosta I, Sarriá C, Gómez I, et al. Influence of Sex on Left-Sided Infective Endocarditis. Rev Esp Cardiol. 2010;63(12):1497-500. doi: 10.1016/s1885-5857(10)70285-1.

5. Murdoch DR, Corey GR, Hoen B, Miró JM, Fowler VG Jr, Bayer AS, et al. Clinical Presentation, Etiology, and Outcome of Infective Endocarditis in the 21st Century: The International Collaboration on Endocarditis-Prospective Cohort Study. Arch Intern Med. 2009;169(5):463-73. doi: 10.1001/archinternmed.2008.603. an increased risk of death in women in the early postoperative period. ${ }^{9}$

The observed higher postoperative mortality in women, apparently not justified by higher burden of comorbidities as it was argued in other series, ${ }^{10}$ should prompt additional investigation to clarify these differences. Moreover, it highlights the importance of finding better tolls for surgical risk evaluation and specific post-operative care after cardiac surgery according to gender.

6. Habib G. Infective Endocarditis in Portugal: Changing Epidemiology but Still a Deadly Disease. Rev Port Cardiol. 2021;40(3):219-20. doi: 10.1016/j.repc.2021.01.006.

7. Sousa C, Nogueira PJ, Pinto FJ. Gender Based Analysis of a Population Series of Patients Hospitalized with Infective Endocarditis in Portugal How do Women and Men Compare?.Int J Cardiovasc Sci. 2021; 34(4):347-355. doi: https://doi.org/10.36660/ijcs.20210032.

8. Bechtel AJ, Huffmyer JL. Gender Differences in Postoperative Outcomes After Cardiac Surgery. Anesthesiol Clin. 2020;38(2):403-15. doi: 10.1016/j.anclin.2020.01.007.

9. Curlier E, Hoen B, Alla F, Selton-Suty C, Schubel L, Doco-Lecompte T, et al. Relationships between Sex, Early Valve Surgery and Mortality in Patients with Left-Sided Infective Endocarditis Analysed in a Population-Based Cohort Study. Heart. 2014;100(15):1173-8. doi: 10.1136/ heartjnl-2013-304916.

10. Weber C, Gassa A, Rokohl A, Sabashnikov A, Deppe AC, Eghbalzadeh K, et al. Severity of Presentation, Not Sex, Increases Risk of Surgery for Infective Endocarditis. Ann Thorac Surg. 2019;107(4):1111-7. doi: 10.1016/j.athoracsur.2018.10.033. 